\title{
Effect of Ammonium Persulfate Concentration on Characteristics of Cellulose Nanocrystals from Oil Palm Frond ${ }^{1}$
}

\author{
Lukmanul Hakim ZAINI ${ }^{2} \cdot$ Fauzi FEBRIANTO ${ }^{2, \dagger} \cdot$ I Nyoman Jaya WISTARA $^{2} \cdot$ \\ Marwanto $\mathrm{N}^{3} \cdot$ Muhammad Iqbal MAULANA ${ }^{3} \cdot$ Seung Hwan $\mathrm{LEE}^{4} \cdot$ Nam Hun KIM(D) ${ }^{4, \dagger}$
}

\begin{abstract}
Cellulose nanocrystals (CNCs) were successfully isolated from oil palm fronds (OPFs) using different concentrations of ammonium persulfate (APS), and their characteristics were analyzed by Fourier transform infrared spectroscopy (FTIR), transmission electron microscopy (TEM), X-ray diffraction (XRD) analysis, and thermogravimetric analysis (TGA). APS oxidation effectively isolated CNCs with rod-like morphology in nanometer scale. The dimensions of the CNCs decreased with increasing APS concentration. FTIR and XRD analyses revealed that all the CNCs showed crystals in the form of cellulose I without crystal transformation occurring during APS treatment. The relative crystallinity of the CNCs increased with increasing APS concentration, whereas their thermal stability decreased. An APS concentration of 2 M was found to be optimal for isolating the CNCs.
\end{abstract}

Keywords: cellulose nanocrystals, oil palm fronds, ammonium persulfate oxidation

\section{INTRODUCTION}

Palm oil industry contributes to the abundant of oil palm solid wastes including empty fruit bunches (EFB), palm kernel shell (PKS), mesocarp fiber (MF), oil palm fronds (OPF), oil palm trunk (OPT), which were obtained from plantation and milling activities (Sukiran et al., 2017). The amount of waste of dry palm oil is estimated to be about 10 ton/ha/year. In addition, a production of 1.5 to 25 million tonnes of dry matter (DM) at the mill and 10 to 50 million tonnes of DM in the plantation of oil palm by-products are estimated. Total percentage of OPF from pruning and cutting activities is $26.5 \%$ of total source (Loh, 2017; Abnisa, 2013). Mathius et al. (2004) has reported that 5,214 kg of dry OPF are produced from 1 ha oil palm plantation

${ }^{1}$ Date Received May 27, 2019, Date Accepted August 13, 2019

2 Department of Forest Products, Faculty of Forestry, Bogor Agricultural University, IPB Dramaga Campus, Bogor, 16680, Indonesia

${ }^{3}$ Forest Products Science and Technology, Department of Forest Products, IPB Graduate School, IPB Dramaga Campus, Bogor, 16680, Indonesia

${ }^{4}$ Department of Forest Biomaterials Engineering, College of Forest and Environmental Science, Kangwon National University, Chuncheon 200-701, Republic of Korea

$\dagger$ Corresponding author: Nam Hun Kim (e-mail: kimnh@kangwon.ac.kr, ORCID: 0000-0002-4416-0554)

$\dagger$ Corresponding author: Fauzi Febrianto (e-mail: febrianto76@yahoo.com, ORCID: 0000-0002-0964-2179) 
Lukmanul Hakim ZAINI • Fauzi FEBRIANTO - I Nyoman Jaya WISTARA • Marwanto N • Muhammad Iqbal MAULANA - Seung Hwan LEE • Nam Hun KIM

a year and their percentage of DM is by $46.18 \%$. Thus, many researchers have developed the utilization of oil palm such as for biopellets (Wistara et al., 2017), densified wood (Hartono et al., 2016a; Hartono et al., 2016b), meanwhile OPF was developed for many applications, i.e. for animal feeds (Ghani et al., 2017; Chanjula et al., 2017), corrosion inhibitors (Shah et al., 2017), succinic acid (Luthfi et al. 2016), biofuel production and biorefineries (Sukiran et al., 2017; Tan et al., 2016), metal ions removal (Zainol et al., 2017), composite board (Khalid et al., 2015; Wardani et al., 2014).

Moreover, OPF with cellulose content of about $43.91 \%$ has a big potential to be raw material of cellulose nanocrystals (CNCs) or cellulose nanofibril (CNF). CNF is a new class of material because of its special characteristics such as high mechanical strength (100-140 Gpa), low density, environtmentally sustainable, high aspect ratio and surface area. CNCs are generally prepared by removing the amorphous area of cellulose, showing 5-70 $\mathrm{nm}$ in diameter and 100-300 nm in length. Similar to CNF, CNCs exhibits a low density $\left(1.6 \mathrm{gcm}^{-3}\right)$, a high specific surface area $\left(300 \mathrm{~m}^{2} \mathrm{~g}^{-1}\right)$, high tensile strength (7.5-7.7 GPa) and elasticity (143 GPa) (Gwon et al., 2018). CNCs have been applied for polymer reinforcement, biomedical application, drug delivery, and so forth.

There are a number of studies related to the isolation and characterization of CNF from OPF and other lignocellulosic material (Dungani et al., 2017; Nordin et al., 2017; Saurabh et al., 2016; Fung et al., 2011; Fung et al., 2010; Park et al., 2016). Likewise, CNCs also have been investigated (Bondeson et al., 2006; Lu and Hsieh, 2010; Zaini, 2013). However, most of isolation methods used acid and/or mechanical process with multiple step. Moreover, the methods have some disadvantages such as the use of highly corrosive mineral acids, tedious isolation techniques, and limitation of large-scale production. In order to avoid the disad- vantages, a simple and versatile one-step procedure using ammonium persulfate (APS) was invented by Leung et al. (2011).

APS is an oxidant with low long-term toxicity, high water solubility and low cost. In order to apply this method, the lignin content of starting material is recommended to be less than $20 \%$. Accordingly, the choice of starting material becomes important. OPFs with less than 20\% lignin content (Leung et al., 2011) can be potencially used as a starting material.

Different conditions such as APS concentration, reaction time and temperature can affect on the characteristics of the resulted CNF. However, The information on the characteristics of CNCs from OPF by APS procedure is still limited.

\section{MATERIALS and METHODS}

\subsection{Materials}

Oil palm fronds (OPF) were obtained from the experimental plot of Dramaga, Bogor, Indonesia. OPF was dried in oven at $105{ }^{\circ} \mathrm{C}$. Next, Dried OPF was grinded using hammer mill and sieved with more than 100 mesh size. APS and $\mathrm{NaOH}$ were purchased from Merck (Jakarta, Indonesia). Aquadest was used as chemical solvent.

\subsection{Preparation of CNCs via APS oxidation}

One liter of different concentration (1, 1.5 and 2 M) of APS was prepared and each of chemical was subjected to $10 \mathrm{~g}$ OPF, which were used as the starting biomass materials. The mixture was heated at $60{ }^{\circ} \mathrm{C}$ for $16 \mathrm{~h}$ under constant mechanical stirring. Centrifugation of the treated suspension was carried out at $12,000 \mathrm{rpm}$ for $10 \mathrm{~min}$. The washing process was repeated four times until the $\mathrm{pH}$ of the suspension was close to 4 . Next, the sample was sonicated using Digital 
Effect of Ammonium Persulfate Concentration on Characteristics of Cellulose Nanocrystals from Oil Palm Frond

Ultrasonic Cleaner, model ST-UB3300LDT in an ice bath for $30 \mathrm{~min}$ prior to lyophilization. The lyophilized sample was stored in a drying cabinet.

\subsection{Transmission Electron Microscope (TEM)}

A drop of diluted cellulose nanofibers suspension stained negatively with $0.5 \%$ aqueous uranyl acetate was deposited onto a carbon-coated $\mathrm{Cu}$ grids and allowed to dry in a desiccator at room temperature. The size and shape of CNCs were studied using a transmission electron microscope (Hitachi, H-7100, Japan) operating at $200 \mathrm{kV}$ in the central laboratory of Kangwon National University.

\subsection{Fourier transform infrared spectroscopy (FTIR)}

FTIR spectra of APS-treated CNCs were obtained using PerkinElmer FTIR spectrophotometer. Samples were ground and mixed well with $\operatorname{KBr}(1: 100, w / w)$, then pressed into thin pellets. FTIR analysis was performed in the transmittance mode with a wavenumber range of $4000-400 \mathrm{~cm}^{-1}$ and a resolution of $4 \mathrm{~cm}^{-1}$ at an accumulation of 32 scans. The positions of the peaks were determined by the OriginPro software.

\subsection{X-ray diffraction (XRD) analysis}

The crystallinities of raw OPF (RO) and APS treated OPF (1M, 1.5M, and 2M) were evaluated by an XRD method. The XRD patterns of the specimens were obtained from an X-ray diffractometer (Shimadzu Maxima XRD-7000) operated at $40 \mathrm{kV}$ and $40 \mathrm{~mA}$ with Ni-filtered $\mathrm{CuKa}$ radiation. X-ray diffractograms were recorded from $2 \theta=10^{\circ}$ to $60^{\circ}$ with the scan rate of $2^{0} / \mathrm{min}$. Crystallinity index (CrI) values were calculated from diffraction intensity data using analytical software XRD 6000/7000. The basis for this method was outlined by Ruland (1961), who determined the crystallinity by subtracting the amorphous contribution from diffraction spectra using an amorphous standard. Ball-milled cellulose was used as an amorphous standard. A scale factor is applied to the spectrum of the amorphous material so that after subtraction of the amorphous spectrum from the original spectrum, no part of the residual spectrum contains a negative signal. Crystallinity Index (CI) is calculated as the ratio between the area of the crystalline contribution and the total area.

\subsection{Thermal analysis}

Thermal properties of the samples were analyzed by a LABSYS evo simultaneous thermal analyzer (STA) from Setaram Instrumentation. Samples were placed in a crucible and heated under nitrogen atmosphere from 35 to $600{ }^{\circ} \mathrm{C}$ with the heating rate of $10{ }^{\circ} \mathrm{C} / \mathrm{min}$.

\section{RESULTS and DISCUSSION}

\subsection{Morphology}

Fig. 1 shows TEM images of CNCs extracted from OPF using different APS concentration. As shown in Fig. 1, the average diameters of all CNCs from OPF were $10 \mathrm{~nm}$ with rod-like shape. TEM images showed that each treatment can be used to isolate CNCs from OPF. Based on cellulose nanofibers calculation, the dimension of the resulted CNCs was different by various APS concentration. 2M had an average length of 350.5 $\mathrm{nm}$ and diameter of $11.1 \mathrm{~nm}$. Meanwhile, 1.5M showed an average length of $564.6 \mathrm{~nm}$ and diameter of 28.6 nm. Finally, 1M exhibited length of $102.2 \mathrm{~nm}$ and diameter of $63.5 \mathrm{~nm}$. $2 \mathrm{M}$ showed the thinnest diameter and shortest length, compared to those from $1 \mathrm{M}$ and 1.5M. This result showed that the dimension of CNCs from OPF was bigger than CNCs extracted from kenaf bast using both sulfuric acid and hydrochloric acid 
Lukmanul Hakim ZAINI • Fauzi FEBRIANTO - I Nyoman Jaya WISTARA • Marwanto N • Muhammad Iqbal MAULANA · Seung Hwan LEE • Nam Hun KIM

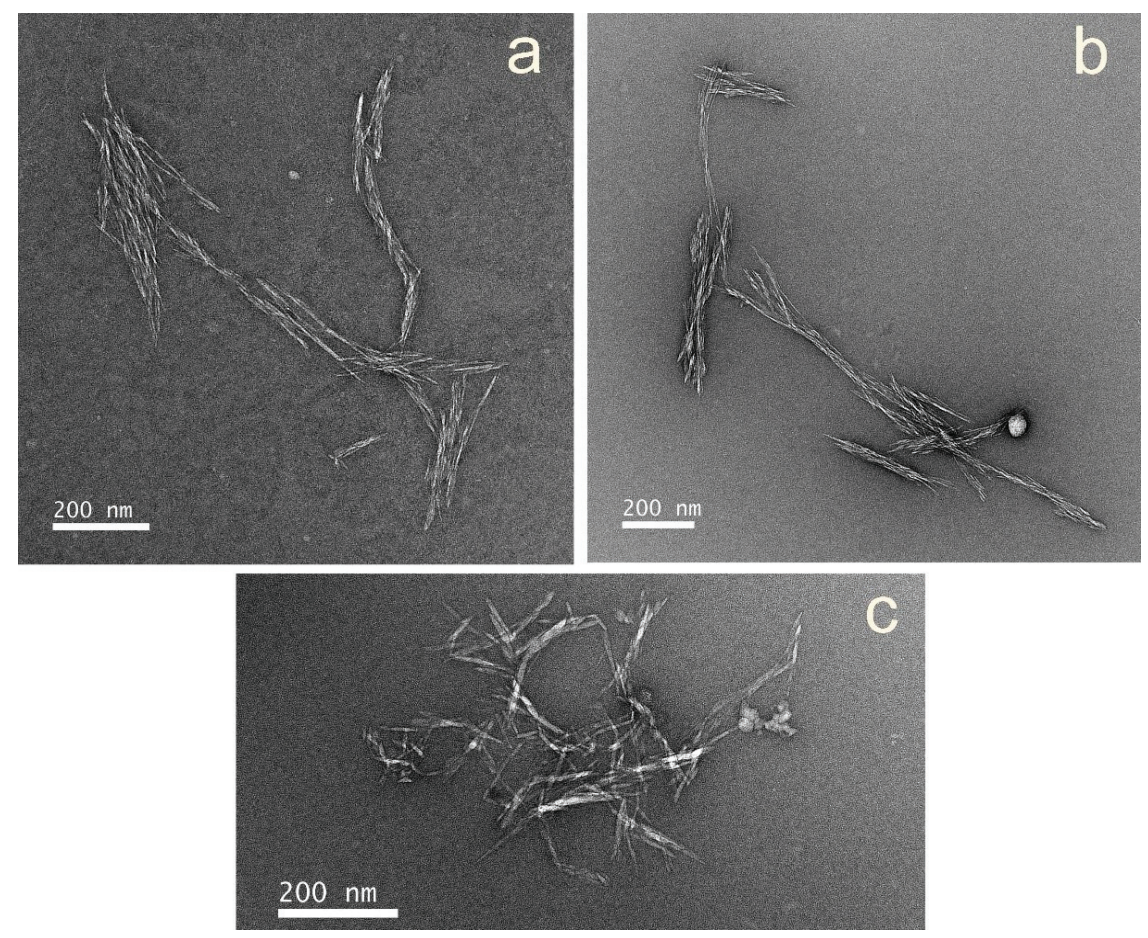

Fig. 1. TEM Images of CNCs prepared using APS (a) $1 \mathrm{M}$, (b) $1.5 \mathrm{M}$ and (c) $2 \mathrm{M}$.

(Zaini et al., 2013).

In terms of average length and diameter of CNCs from OPF, 2M has shown the highest aspect ratio (diameter to length) while $1 \mathrm{M}$ was the lowest. The higher APS concentration was resulted in big aspect ratio of CNCs. $2 \mathrm{M}$ were expected to have a high reinforcing capability due to the aspect ratio compared to other treatment. Zaini et al. (2014) mentioned that the increament of kenaf CNCs into cellulose acetate butyrate matrix led to a higher storage modulus of resulted composite.

\subsection{FTIR analysis}

FTIR spectra of RO and OPFCNCs are shown in Fig. 2. All spectra revealed similar characteristics. There is no considerable change of the conformation of the cellulose structure. A wide and intense peak between
$3000-3700 \mathrm{~cm}^{-1}$ region which is shown in all spectra was assigned to the $\mathrm{O}-\mathrm{H}$ bonds streching of polysaccharides (Castro-Guerrero and Gray, 2014; Goh et al., 2016; Jiang et al., 2017; Jo et al., 2016). The peak at around $1430 \mathrm{~cm}^{-1}$ is due to scissoring motion of $\mathrm{CH}_{2}$ representing crystalline region. In addition, the peak at around $1160 \mathrm{~cm}^{-1}$ is ascribed C-O-C bonding of ß-glucosidic bond (Castro-Guerrero and Gray, 2014; Goh et al., 2016; Jiang et al., 2017; Jo et al., 2016). Moreover, The vibration peak at $898 \mathrm{~cm}^{-1}$ is attributed to $\mathrm{C}-\mathrm{H}$ stretching out of plane ring which are symmetric in polysaccharides of cellulose due to $\beta$ -linkage or the glycoside bonds (Adel et al., 2011; Troedec et al., 2008; Castro-Guerrero and Gray, 2014; Goh et al., 2016; Jiang et al., 2017). All spectra showed the characteristics of typical cellulose I (Zaini et al., 2013; Tahir et al., 2015; Castro-Guerrero and Gray 2014; Goh et al., 2016; Jiang et al., 2017; Oun et al., 2017). 


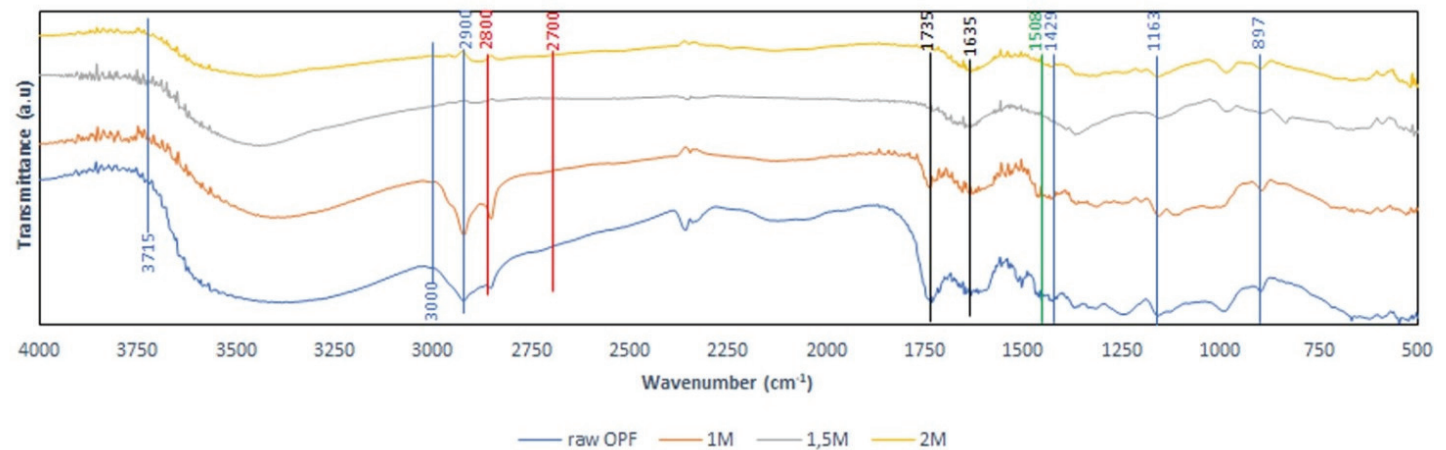

Fig. 2. FTIR Spectra of resulted raw OPF and OPF CNCs.

The peak at $1508 \mathrm{~cm}^{-1}$ is appointed for $\mathrm{C}=\mathrm{C}$ of the aromatic ring of lignin (Troedec et al., 2008; Goh et al., 2016; Jiang et al., 2017), which is present only in RO spectra. This indicates that lignin was removed after APS treatment in all chemical concentration. In addition, the peak at $1735 \mathrm{~cm}^{-1}$ in the RO and 1 Mare assigned to the $\mathrm{C}=\mathrm{O}$ stretching of the acetyl and uronic ester groups of hemicelluloses and the ester linkage of the carboxylic groups of the ferulic and p-coumaric acids of lignin and/or hemicellulose (Biagiotti et al., 2004; Liu et al., 2004; Sun et al., 2005; Goh et al., 2016; Jo et al., 2016). The highest intensity of this peak was in RO, decreased in $1 \mathrm{M}$ and disappeared in $1.5 \mathrm{M}$ and $2 \mathrm{M}$. The disappearance of this peak indicates that lignin and hemicellulose were completely removed.

The intensity of the peak due to waxes and oils at $2850 \mathrm{~cm}^{-1}$ was decreased as APS concentration increased (Troedec et al., 2008; Castro-Guerrero and Gray, 2014; Goh et al., 2016). No peak was observed in the $2800-2700 \mathrm{~cm}^{-1}$ range ascribable to aldehyde or ketone groups (Castro-Guerrero and Gray, 2014), indicating that no aldehyde or ketone groups occurred in the resulted CNCs.

Spectra around $1635 \mathrm{~cm}^{-1}$ is ascribed to $\mathrm{C}=\mathrm{O}$ band which is corresponding to the sodium carboxylate $\left(\mathrm{COO}^{-} \mathrm{Na}^{+}\right)$occurred during neutralization of $\mathrm{CNCs}$ with
$\mathrm{NaOH}$ (Castro-Guerrero and Gray, 2014; Oun et al., 2017). The oxidation is also indicated by the presence of the $\mathrm{C}=\mathrm{O}$ band.

\subsection{Crystallinity index}

The X-ray diffraction profiles of RO and CNCs are shown in Fig. 3. All diffractograms showed the reflections at $2 \theta=14.7^{\circ}, 16.2^{\circ}$, and $22.7^{\circ}$, attributed to the (1-10), (110) and (200) crystallographic planes of typical cellulose I while the amorphous phases ascribed by reflection at $18^{\circ}$ (Leung et al., 2011; Oun and Rhim, 2015; Tahir, 2015; Jiang et al., 2017). It was indicating that APS treatment does not change the crystal structure of cellulose I in OPF. This result was also supporting previous FTIR analysis result.

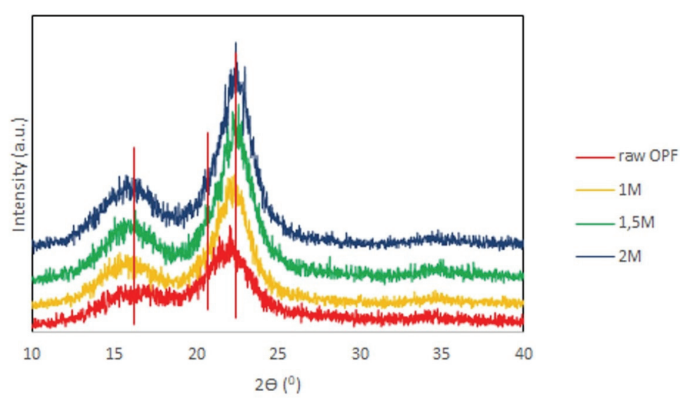

Fig. 3. Equatorial X-ray diffractograms of RO and OPF CNCs. 
Lukmanul Hakim ZAINI • Fauzi FEBRIANTO - I Nyoman Jaya WISTARA • Marwanto N • Muhammad Iqbal MAULANA · Seung Hwan LEE - Nam Hun KIM

Table 1. Crystallinity index of raw OPF and OPF CNCs

\begin{tabular}{cc}
\hline Concentration of APS & CRI \\
\hline \hline Raw OPF & $26.5 \%$ \\
$1 \mathrm{M}$ & $49.7 \%$ \\
$1.5 \mathrm{M}$ & $51.3 \%$ \\
$2 \mathrm{M}$ & $52.4 \%$ \\
\hline
\end{tabular}

The crystallinity index (CRI) can be seen in Table 1 . The Ruland-Vonk method was preferred for crystallinity determination since it provides a more accurate measure of the crystallinity by analyzing the contributions from both amorphous and crystalline cellulose of the XRD diffraction pattern (Park et al., 2010). The crystallinity of CNCs was increased as APS concentration increased. The removal of lignin and hemicelluloses from RO were responsible for the increasing of the crystallinity. Moreover, the removal ability of amorphous area of cellulose after APS treatment must be increased as the concentration of APS increased.

$1 \mathrm{M}, 1.5 \mathrm{M}$ and $2 \mathrm{M}$ had double crystallinity compared to RO. The crystallinity index of APS treated fibers was studied using many samples such as flax $75 \%$, flax shives $64 \%$, hemp and triticale $73 \%$, microcrystalline cellulose $83 \%$, wood pulp $81 \%$, bacterial cellulose 70\% (Leung et al., 2011). However, all resulted CNCs crystallinity indicated lower value compared to all samples previously mentioned. XRD integral method used by Leung et al. (2011) produces values that are significantly higher than CRI calculation in this study (Park et al., 2016). Meanwhile, as a comparison, cellulose nanofibers isolated from various sources were exhibited crystallinity index of kenaf core 62\% (Jonoobi, 2010), kenaf bast 72\% (Zaini et al., 2013), cotton 85\% (Castro-Guerrero and Gray, 2014), microfibrilllated cellulose 76\% (Goh et al., 2016), and cotton linter 93.5\% (Oun and Rhim, 2017).

\subsection{Thermal stability}

As reinforcement material, thermal stabilities of CNCs are important particularly to fulfill minimal thermal acceptance in composite material processing. Depending on the type of matrix/binder used, generally biocomposites are manufactured at temperature between 150 to $300{ }^{\circ} \mathrm{C}$. Minimum thermal acceptance in composite processing usually needs temperature around 180 $-200{ }^{\circ} \mathrm{C}$ (Mohanty et al., 2000).

Fig. 4 shows TG and DTG thermograms of RO, 1M, $1.5 \mathrm{M}$, and $2 \mathrm{M}$. All thermograms were shifted to the lower temperature as the APS concentration increase. RO and $1 \mathrm{M}$ were observed to start degrading at $165^{\circ} \mathrm{C}$ inferring degradations of both hemicellulose and lignin. Hemicellulose is starting to decompose at around 200 ${ }^{0} \mathrm{C}$ while lignin degrades in a wider temperature ranging
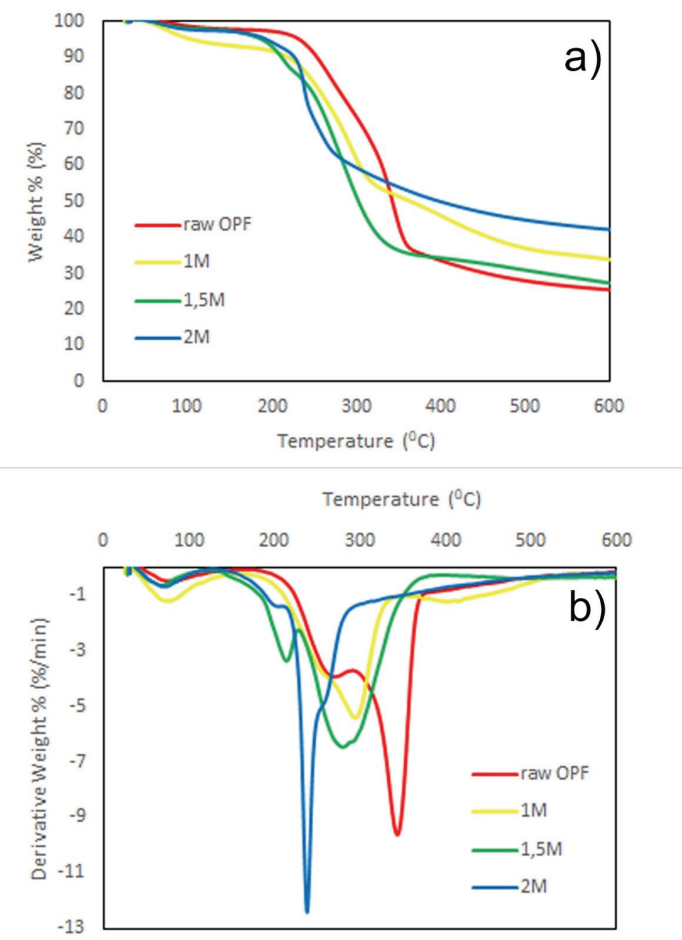

Fig. 4. TGA (a) and DTG (b) of raw OPF and OPF CNCs. 
Effect of Ammonium Persulfate Concentration on Characteristics of Cellulose Nanocrystals from Oil Palm Frond

Table 2. Decomposition temperature $\left(\mathrm{T}_{\mathrm{dec}}\right)$ and maximum degradation temperature $\left(\mathrm{T}_{\operatorname{maxd}}\right)$ of raw OPF and resulted CNCs

\begin{tabular}{ccc}
\hline & $\operatorname{Tdec}\left({ }^{\circ} \mathrm{C}\right)$ & $\operatorname{Tmaxd}\left({ }^{\circ} \mathrm{C}\right)$ \\
\hline \hline OPF & 344 & $400-600$ \\
$1 \mathrm{M}$ & 297 & $350-600$ \\
$1,5 \mathrm{M}$ & 279 & $400-600$ \\
$2 \mathrm{M}$ & 238 & $350-600$ \\
\hline
\end{tabular}

from 100 to $900{ }^{\circ} \mathrm{C}$ (Yang et al., 2007). Upon the primary region, degradation of cellulosic material occurred at the temperatures as shown in Table 2 .

Decomposition termperature was decreased as much as $14 \%, 19 \%$, and $31 \%$ for $1 \mathrm{M}, 1.5 \mathrm{M}$, and $2 \mathrm{M}$, respectively. The possible reason of thermal stability decreasing as APS concentration increase might be explained by increasinglarge surface area because of particle size decrease (Goh et al., 2016; Oun and Rhim, 2017). Low degree of polymerization inclined to degrade at low temperatures. Furthermore, $1.5 \mathrm{M}$ and 2M show peaks between temperature $200-250{ }^{\circ} \mathrm{C}$ are suspected to be instigated by the presence of sodium carboxyl groups on the surface of CNCs (Oun and Rhim, 2017). However, all the results in this study still met the minimum requirement of composite processing since minimum thermal acceptance usually needs temperature around $180-200{ }^{\circ} \mathrm{C}$. After the temperature reaches 400 ${ }^{\circ} \mathrm{C}$, cellulose will be fully degraded, transformed to gaseous products and $\mathrm{CO}_{2}$ with non-combustible residues (Oun and Rhim, 2017).

\section{CONCLUSION}

In this study, CNCs were successfully isolated from OPF using one-step procedure using APS. Needle-like CNCs with tendency to agglomerate showed the diameter ranging from 11 to $63 \mathrm{~nm}$ and length from 100 to $600 \mathrm{~nm}$. Concentration of 2 M APS treatment showed the optimal condition for isolating CNCs with thinnest diameter and highest aspect ratio. FTIR and $\mathrm{XRD}$ analyses showed no change on the original crystal structures during the oxidation process. Crystallinity was increased as the APS concentration increased while thermal stability decreased.

\section{ACKNOWLEDGMENT}

We sincerely acknowledge Directorate of Higher Education (DIKTI), Ministry of Research, Technology, and Higher Education, Republic of Indonesia for the financial support given through Excellent Research Program of University (No. 011/SP2H/LT/DRPM/IV/ 2017). This research was also supported by Science and Technology Support Program through the National Research Foundation of Korea (NRF) funded by the Ministry of Science and ICT (MSIT) (NRF-2019K1A 3A9A01000018) and also supported by Basic Science Research Program through NRF funded by the Ministry of Education (No. 2018R1A6A1A03025582).

\section{REFERENCES}

Abnisa, F., Arami-Niya, A., Daud, W.W., Sahu, J., Noor, I. 2013. Utilization of oil palm tree residues to produce bio-oil and bio-char via pyrolysis. Energy Convers Manage 76: 1073-1082.

Adel, A.M., Abd El-Wahab, Z.H., Ibrahim, A.A., Al-Shemy, M.T. 2011. Characterization of microcrystalline cellulose prepared from lignocellulosic materials. Part II: Physicochemical properties. Carbohydrate Polymers 83(2): 676-687.

Biagiotti, J., Puglia, D., Torre, L., Kenny, J.M., Arbelaiz, A., Cantero, G., Marieta, C., Llano-Ponte, R., Mondragon, I. 2004. A systematic investigation on the influence of the chemical treatment of natural fibers on the properties of their polymer matrix composites. Polymer Composites 25(5): 470-479. 
Lukmanul Hakim ZAINI - Fauzi FEBRIANTO - I Nyoman Jaya WISTARA • Marwanto N • Muhammad Iqbal MAULANA - Seung Hwan LEE • Nam Hun KIM

Bondeson, D., Mathew, A., Oksman, K. 2006. Optimization of the isolation of nanocrystals from microcrystalline cellulose by acid hydrolysis. Cellulose 13(2): 171-180.

Castro-Guerrero, C.F., Gray, D.G. 2014. Chiral nematic phase formation by aqueous suspensions of cellulose nanocrystals prepared by oxidation with ammonium persulfate. Cellulose 21(4): 2567-2577.

Chanjula, P., Petcharat, V., Cherdthong, A. 2017. Effects of fungal (Lentinussajor-caju) treated oil palm frond on performance and carcass characteristics in finishing goats. Asian-Australasian journal of animal sciences 30(6): 811-818.

Dungani, R., Owolabi, A.F., Saurabh, C.K., Khalil, H.A., Tahir, P.M., Hazwan, C.I.C.M., Aditiawati, P. 2017. Preparation and fundamental characterization of cellulose nanocrystal from oil palm fronds biomass. Journal of Polymers and the Environment 25(3): 692-700.

Fung, W.Y., Yuen, K.H., Liong, M.T. 2010. Characterization of fibrous residues from agrowastes and the production of nanofibers. Journal of agricultural and food chemistry 58(13): 8077-8084.

Fung, W.Y., Yuen, K.H., Liong, M.T. 2011. Agrowastebased nanofibers as a probiotic encapsulant: fabrication and characterization. Journal of agricultural and food chemistry 59(15): 8140-8147.

Ghani, A.A.A., Rusli, N.D., Shahudin, M.S., Goh, Y.M., Zamri-Saad, M., Hafandi, A., Hassim, H.A. 2017. Utilisation of Oil Palm Fronds as Ruminant Feed and Its Effect on Fatty Acid Metabolism. Pertanika Journal of Tropical Agricultural Science 40(2): 215-224.

Goh, K.Y., Ching, Y.C., Chuah, C.H., Abdullah, L.C., Liou, N.S. 2016. Individualization of microfibrillated celluloses from oil palm empty fruit bunch: Comparative studies between acid hydrolysis and ammonium persulfate oxidation. Cellulose 23(1): 379-390.
Gwon, J.G., Lee, D.B., Cho, H.J., Lee, S.Y. 2018. Preparation and Characteristics of Cellulose Acetate Based Nanocomposites Reinforced with Cellulose Nanocrystals (CNCs). Journal of the Korean Wood Science and Technology 46(5): 565-576.

Hartono, R., Hidayat, W., Wahyudi, I., Febrianto, F., Dwianto, W., Jang, J.H., Kim, N.H. 2016a. Effect of Phenol Formaldehyde Impregnation on The Physical and Mechanical Properties of Soft-Inner Part of Oil Palm Trunk. Journal of the Korean Wood Science and Technology 44(6): 842-851.

Hartono, R., Wahyudi, I., Febrianto, F., Dwianto, W., Hidayat, W., Jang, J.H., Kim, N.H. 2016b. Quality Improvement of Oil Palm Trunk Properties by Close System Compression Method. Journal of the Korean Wood Science and Technology 44(2): 172-183.

Jiang, H., Wu, Y., Han, B., Zhang, Y. 2017. Effect of oxidation time on the properties of cellulose nanocrystals from hybrid poplar residues using the ammonium persulfate. Carbohydrate polymers 174: 291-298.

Jo, J., Jung, J., Byun, J., Lim, B., Yang, J. 2016. Preparation of cellulose acetate produced from lignocellulosic biomass. Journal of the Korean Wood Science and Technology 44(2): 241-252.

Jonoobi, M., Harun, J., Tahir, P.M., Zaini, L.H., SaifulAzry, S., Makinejad, M.D. 2010. Characteristic of nanofibers extracted from kenaf core. BioResources 5(4): 2556-2566.

Khalid, I., Sulaiman, O., Hashim, R., Razak, W., Jumhuri, N., Rasat, M.S.M. 2015. Evaluation on layering effects and adhesive rates of laminated compressed composite panels made from oil palm (Elaeis guineensis) fronds. Materials \& Design 68: 24-28.

Leung, A.C., Hrapovic, S., Lam, E., Liu, Y., Male, K.B., Mahmoud, K.A., Luong, J.H. 2011. Charac- 
Effect of Ammonium Persulfate Concentration on Characteristics of Cellulose Nanocrystals from Oil Palm Frond

teristics and properties of carboxylated cellulose nanocrystals prepared from a novel one-step procedure. Small 7(3): 302-305.

Liu, W., Mohanty, A.K., Drzal, L.T., Askel, P., Misra, M. 2004. Effects of alkali treatment on the structure, morphology and thermal properties of native grass fibers as reinforcements for polymer matrix composites. Journal of Materials Science 39(3): 1051-1054.

Loh, S.K. 2017. The potential of the Malaysian oil palm biomass as renewable energy source. Energy conversion and management 141: 285-298.

Lu, P., Hsieh, Y.L. 2010. Preparation and properties of cellulose nanocrystals: rods, spheres, and network. Carbohydrate polymers 82(2): 329-336.

Luthfi, A.A.I., Jahim, J.M., Harun, S., Tan, J.P., Mohammad, A.W. 2016. Biorefinery approach towards greener succinic acid production from oil palm frond bagasse. Process Biochemistry 51(10): 1527-1537.

Mathius, I.W., Sitompul, D., Manurung, B.P., Azmi. 2004. By-products of plant and processing of palm oil as a feed for beef cattle: A review. In Pros. National Workshop on Palm Oil-Cattle Integration System. Agricultural Research Agency of the Government of Bengkulu Province and PT. Agricinal. 120-128.

Mohanty, A.K., Misra, M., Hinrichsen, G. 2000. Biofibres, biodegradable polymers and biocomposites: An overview. Macromolecular Materials and Engineering 276(1): 1-24.

Nordin, N.A., Sulaiman, O., Hashim, R., Kassim, M.H.M. 2017. Oil Palm Frond Waste for the Production of Cellulose Nanocrystals. Journal of Physical Science 28(2): 115-126.

Oun, A.A., and Rhim, J.W. 2015. Preparation and characterization of sodium carboxymethyl cellulose/ cotton linter cellulose nanofibril composite films. Carbohydrate polymers 127: 101-109.
Oun, A.A., and Rhim, J.W. 2017. Characterization of carboxymethyl cellulose-based nanocomposite films reinforced with oxidized nanocellulose isolated using ammonium persulfate method. Carbohydrate polymers 174: 484-492.

Park, S., Baker, J.O., Himmel, M.E., Parilla, P.A., Johnson, D.K. 2010. Cellulose crystallinity index: measurement techniques and their impact on interpreting cellulase performance. Biotechnology for biofuels 3(10): 1-10.

Park, C.W., Han, S.Y., Lee, S.H. 2016. Size Fractionation of Cellulose Nanofibers by Settling Method and Their Morphology. Journal of the Korean Wood Science and Technology 44(3): 398-405.

Ruland, W. 1961. X-ray determination of crystallinity and diffuse disorder scattering. Acta Cryst 1961 14:1180-1185.

Saurabh, C.K., Dungani, R., Owolabi, A.F., Atiqah, N.S., Zaidon, A., Aprilia, N.S., Khalil, H.A. 2016. Effect of hydrolysis treatment on cellulose nanowhiskers from oil palm (Elaeis guineesis) fronds: morphology, chemical, crystallinity, and thermal characteristics. BioResources 11(3): 6742-6755.

Shah, A.M., Rahim, A.A., Ibrahim, M.N.M., Hussin, M.H. 2017. Depolymerized Oil Palm Frond (OPF) Lignin Products as Corrosion Inhibitors for Mild Steel in $1 \mathrm{M} \mathrm{HCl}$. International Journal of Electrochemical Science 12(10): 9017-9039.

Sukiran, M.A., Abnisa, F., Daud, W.M. A.W., Bakar, N.A., Loh, S.K. 2017. A review of torrefaction of oil palm solid wastes for biofuel production. Energy conversion and management 149: 101-120. Sun, X.F., Xu, F., Sun, R.C., Fowler, P. and Baird, M.S. 2005. Characteristics of degraded cellulose obtained from steam-exploded wheat straw. Carbohydrate Research 340(1): 97-106.

Tahir, P.M., Zaini, L.H., Jonoobi, M., Khalil, H.A. 2015. Preparation of Nanocellulose from Kenaf (Hibiscus cannabinus L.) via Chemical and Chemo- 
Lukmanul Hakim ZAINI - Fauzi FEBRIANTO - I Nyoman Jaya WISTARA • Marwanto N • Muhammad Iqbal MAULANA · Seung Hwan LEE • Nam Hun KIM

mechanical Processes. In: Handbook of Polymer Nanocomposites: Processing, Performance and Application. Ed. by Pandey, J. K., Takagi, H., Antonio, Nakagaito, N., Kim, H., Springer-Verlag Berlin Heidelberg, Germany.

Tan, J.P., Jahim, J.M., Harun, S., Wu, T.Y., Mumtaz, T. 2016. Utilization of oil palm fronds as a sustainable carbon source in biorefineries. International Journal of Hydrogen Energy 41(8): 48964906.

Troedec, M.L., Sedan, D., Peyratout, C., Bonnet, J.P., Smith, A.S., Guinebretiere, R., Gloaguen, V., Krausz, P. 2008. Influence of various chemical treatments on the composition and structure of hemp fibres. Composites Part A: Applied Science and Manufacturing 39(3): 514-522.

Wardani, L., Massijaya, M.Y., Hadi, Y.S., Darmawan, I.W. (2014). The Effect of Zephyr Layer Orientation on Zephyrboard Made from Oil Palm Petiole. Makara Journal of Technology 18(1): 36-40.

Wistara, N.J., Rohmatullah, M.A., Febrianto, F., Pari, G., Lee, S., Kim, N. 2017. Effect of bark content and densification temperature on the properties of oil palm trunk-based pellets. Journal of the Korean Wood Science and Technology 45(6): 671-681. Yang, H., Yan, R., Chen, H., Lee, D.H., Zheng, C. 2007. Characteristics of hemicellulose, cellulose and lignin pyrolysis. Fuel 86(12-13): 1781-1788.

Zaini, L. H., Jonoobi, M., Tahir, P. M., Karimi, S. 2013. Isolation and Characterization of Cellulose Whiskers from Kenaf (Hibiscus cannabinus L.) Bast Fibers. Journal of Biomaterials and Nanobiotechnology 4(1): 37-44.

Zaini, L.H., Paridah, M.T., Jawaid, M., Othman, A. Y., Juliana, A.H. 2014. Effect of Kenaf Cellulose Whiskers on Cellulose Acetate Butyrate Nanocomposites Properties. In: Nanocellulose Polymer Nanocomposites: Fundamentals and Applications. Ed. by Thakur, V.K., Scrivener Publishing LLC, Beverly, USA.

Zainol, M.M., Amin, N.A.S., Asmadi, M. 2017. Preparation and Characterization of Impregnated Magnetic Particles on Oil Palm Frond Activated Carbon for Metal Ions Removal. Sains Malaysiana 46(5): 773-782. 